\title{
Results from a normative dependency analysis of geographic information standards
}

\author{
Serena Coetzee* \\ Department Computer Science, University of Pretoria, Pretoria, 0002, South Africa
}

\begin{abstract}
Standardization in the field of geographic information started in the 1990s when geographic information systems (GIS) matured and the advent of the Internet accelerated the exchange of information. Recent developments, such as location-based services and the use of the Global Positioning System (GPS) on handheld devices, have further increased the demand for standardization in the field. ISO/TC 211, Geographic information/Geomatics develops the ISO 19100 series of geographic information standards and collaborates with other standards organizations, for example, by developing abstract standards for which the Open Geospatial Consortium (OGC) develops implementation specifications. To date, forty nine ISO 19100 standards have been published. Many of these were recently approved for revision. One of the challenges of standard maintenance is to determine whether a change in a revised standard affects other standards, and how. Object dependency analysis is commonly used in objectoriented software maintenance. Geographic information standards, however, are not composed purely of objects. Instead, dependencies in all the normative elements of the standard have to be analyzed and understood. This paper presents the novel approach of a normative dependency analysis for standard maintenance in which interdependencies between the normative elements of standards are analyzed. In the paper a normative dependency between two standards is defined for the first time, a notation for normative dependencies is introduced, a normative dependency data model is presented and results from a normative dependency analysis of the ISO 19100 geographic information standards are discussed. The paper concludes with results, applicable to any suite of standards, and a discussion of further work.
\end{abstract}

Keywords: standard, geographic information, standard maintenance, dependency analysis, harmonization

\section{Introduction}

Standardization in the field of geographic information started in the 1990s when geographic information systems (GIS) matured and the advent of the Internet accelerated the sharing and exchange of information. In 1994, a technical committee for standardization in the field of geographic information was created in the International Organization for Standardization (ISO), the ISO/TC 211 Geographic information/Geomatics [1]. The first standard was published in 2000 and since then, a suite of standards for geographic information has been published by ISO/TC 211; the first ISO number assigned is 19101 and the number of the latest project under development is 19160. More than half of the 49 published standards have undergone ISO's periodic systematic review in the past few years. Only four of these were confirmed; based on the comments received in the systematic reviews, it was decided that most of the others should be revised and some of these revisions have already commenced. Typically, ISO/TC 211 prepares abstract standards that describe the conceptual components of a standard and the relationships between these components.

The Open Geospatial Consortium, Inc (OGC) is an international industry consortium with more than 400 members, including companies, government agencies and universities [2]. OGC, founded in 1994, focuses on the publication of implementation specifications. OGC was one of the first liaisons approved by ISO/TC 211 in 1995. Since 2003 collaboration is coordinated through a Joint Advisory Group (JAG). OGC publications include quite a few implementation specifications for abstract standards that are published by ISO/TC211. For example, the OGC 
implementation specification for a gazetteer service [3] which is based on the conceptual model for gazetteers defined in ISO 19112, Geographic information - Spatial referencing by geographic identifiers [4]. Others are jointly developed standards, such as ISO 19128:2005, Geographic information - Web Map Service Interface [5], which has been published by the OGC as OpenGIS® Web Map Server Implementation Specification 1.3.0 [6].

A spatial data infrastructure aims to make spatial (geographic) data usable by as wide an audience as possible. The implementation of spatial data infrastructures in countries, regions and globally has created a demand for a suite of harmonized geographic information standards. One such example is the INfrastructure for SPatial InfoRmation in Europe (INSPIRE), which aims to create a European Union (EU) spatial data infrastructure that will enable the sharing of environmental spatial information among public sector organizations and better facilitate public access to spatial information across Europe [7]. INSPIRE specifications extensively normatively reference ISO 19100 standards. Omnipresence of digital geographic information on Internet Mapping sites (Google Earth, VirtualEarth and OpenStreetMap) and handheld devices (cell phones and GPS devices) further contributes towards the demand for a suite of harmonized geographic information standards.

One of the challenges of standard harmonization is the maintenance of standards when revisions are required. It is a challenge to determine whether a change in a revised standard affects other standards, and how. A standard describes how it depends on other standards, but understanding how other standards depend on a specific standard is not described in a single document. Due to the collaboration with other organizations, publications by other standardization organizations (i.e. other than ISO/TC 211) could also depend on an ISO 19100 standard and to complicate matters further, there could be a chain of dependencies involved.

The work on normative dependencies was initiated in the Programme Maintenance Group (PMG) of ISO/TC 211. The group coordinates efforts in the committee to ensure harmonization and consistency of standards and alignment with changing requirements and technological developments. A normative dependency analysis as tool in support of standard maintenance was researched and the results are reported here.

Dependency analysis is commonly used in software maintenance to understand the architectural interdependencies of software systems. For example, an object-oriented system is composed of a collection of communicating objects. Analyzing objects and their relationships facilitates an in-depth understanding of object-oriented software systems. For systems consisting of large quantities of objects, reverse engineering tools can create package diagrams by grouping classes into packages. A different approach aggregates the complete static description of software objects so that each coarse-grained entity represents a set of objects. A dependency between coarse-grained entities indicates a possible relationship between the objects they represent [8].

The Harmonized Maintenance Management Group (HMMG) of ISO/TC 211 maintains a harmonized model of all UML elements in ISO 19100 standards. The dependencies between packages in this model could be analyzed by following the approaches above, but the approaches are lacking for standard maintenance in other areas. Standards are not composed purely of objects and the above approaches do not detect dependencies that are embedded in the normative text of a standard. Dependencies in all normative elements (title, scope, terms, provisions, etc.) of the standard have to be included in an analysis and considered for standard maintenance. Dependencies in the informative content of a standard on the other hand can be ignored. [9] concur with our observation that standards are sometimes large text documents that are difficult to intertpret. They propose a framework for achieving and assessing conformance to such standards. Their solution includes an analysis of the interrelationships between the requirements within a standard, but not among different standards. 
This paper presents the novel approach of a normative dependency analysis, in which relationships between normative elements of standards are analyzed, and shows how such an analysis enables an in-depth understanding of standard interdependencies, necessary for standard maintenance. The remainder of the paper is structured as follows: section 2 defines a normative dependency between two standards and introduces a notation for these; section 3 presents the normative dependency data model and describes how the normative dependency analysis was conducted; section 4 discusses results from the normative dependency analysis; and section 5 concludes with a summary of results and a discussion of further work.

\section{Normative dependencies between standards}

At a high level, an ISO standard consists of normative and informative elements. Normative elements describe the scope of the document and set out provisions of the standard, while informative elements provide additional information to introduce the content, explain the background and assist in understanding and using the document [10]. Only changes to the normative content of a standard can possibly have an impact on other standards, therefore it is sufficient to analyze dependencies in the normative content in order to understand the impact of a change introduced in a revision. Thus, a normative dependency is a relationship between two standards where a change to the normative content in the one standard affects the normative content of the other standard.

Table 1

Definition and notation of normative dependencies

\begin{tabular}{|c|c|c|}
\hline Dependency & Notation & Definition \\
\hline \multirow[t]{2}{*}{ Scope } & $\mathrm{S}_{1}: \mathrm{YYYY} \underline{\text { Scope }}>\mathrm{S}_{2}: \mathrm{YYYY}[$ dependency] & $\begin{array}{l}\text { The scope statement of } S_{1}: Y Y Y Y \text { has a } \\
\text { dependency on } S_{2}: Y Y Y Y\end{array}$ \\
\hline & $\mathrm{S}_{1}: \mathrm{YYYY} \underline{\underline{\text { scope }}>\mathrm{S}_{2}[\text { dependency] }}$ & $\begin{array}{l}\text { The scope statement of } S_{1} \text { :YYYY has a } \\
\text { dependency on } S_{2}\end{array}$ \\
\hline $\begin{array}{l}\text { Normative } \\
\text { reference }\end{array}$ & $\mathrm{S}_{1}: \mathrm{YYYY} \underline{\mathrm{NRref}}>\mathrm{S}_{2}$ & $\begin{array}{l}\mathrm{S}_{1}: Y Y Y Y \text { normatively references } \mathrm{S}_{2} \text { (dated } \\
\text { dependency) }\end{array}$ \\
\hline Term & $\mathrm{S}_{1}: \mathrm{YYYY} \underline{\text { Term }}>\mathrm{S}_{2}[$ term $]$ & $\begin{array}{l}S_{1}: Y Y Y Y \text { repeats the definition of a term } \\
\text { defined in } S_{2}\end{array}$ \\
\hline \multirow[t]{4}{*}{ Provision } & $\mathrm{S}_{1}: \mathrm{YYYY}$ Requirement $>\mathrm{S}_{2}$ [requirement] & $\begin{array}{l}\text { A requirement in } S_{1}: Y Y Y Y \text { has a } \\
\text { dependency on } S_{2}\end{array}$ \\
\hline & $\mathrm{S}_{1}: \mathrm{YYYY}$ Recommendation $>\mathrm{S}_{2}[$ recommendation $]$ & $\begin{array}{l}\text { A recommendation in } S_{1}: Y Y Y Y \text { has a } \\
\text { dependency on } S_{2}\end{array}$ \\
\hline & $\mathrm{S}_{1}: \mathrm{YYYY} \stackrel{\text { RequirementUML }}{>} \mathrm{S}_{2}[U M L$ element $]$ & $\begin{array}{l}\text { A requirement in } S_{1}: Y Y Y Y \text { depends on a } \\
\text { UML element from } S_{2}\end{array}$ \\
\hline & $\mathrm{S}_{1}: \mathrm{YYYY}$ RecommendationUML $>\mathrm{S}_{2}$ [UML element $]$ & $\begin{array}{l}\text { A recommendation in } S_{1}: Y Y Y Y \text { depends on } \\
\text { a UML element from } S_{2}\end{array}$ \\
\hline
\end{tabular}

Normative elements of a standard include the title, scope, normative references, terms and definitions, symbols and abbreviated terms, and provisions. Table 1 shows the definition of different kinds of normative dependencies between standards. While the title of a standard is a normative element, it does not include dependencies on other standards (or if, these will be repeated in the scope, thus working with scope dependencies is sufficient). Table 1 also introduces a notation for normative dependencies. In the notation $S: Y Y Y Y$ is a specific edition of a standard, where $Y Y Y Y$ is the year of publication. $S$ collectively refers to all editions, $S: Y Y Y Y$, of $S$. The details of the dependency are given (in free text) between the square brackets that follow. A normative dependency with an $S: Y Y Y Y$ on the right hand side can also be referred to as a 
dated normative dependency, while with only the $S$ on the right hand side, it is an undated normative dependency. For the scope dependency, the notation for both the dated and undated dependency is shown in the table, while (for simplicity reasons) only the undated dependency is shown for the other kinds of normative dependencies. Table 2 gives examples from published standards for each one of the dependencies.

The scope statement of a standard defines the subject of the document and the aspects covered, thereby indicating the limits of applicability of the document or particular parts of it [10]. In some cases the scope statement specifies a dependency on another standard. For example, the scope of an implementation specification could depend on an abstract standard.

Normative references are 'referenced documents cited in the document in such a way as to make them indispensable for the application of the document' [10], implying that a change to the normatively referenced document will change the way in which the document in which it is normatively referenced, is understood and interpreted. In an ISO standard only a reference to the other document is included; no information about the details of the dependency is supplied (i.e. no square brackets in the notation). This is the only kind of normative dependency where the details of the dependency are not provided.

The normative element of a standard that contains the terms and definitions includes a normative dependency if a term and its definition are repeated from another document. The reference to the other document could be dated, $S_{1}: Y Y Y Y$ Term $>S_{2}: Y Y Y Y$, indicating that the term is repeated from a specific edition of the standard, or undated, $S_{1}: Y Y Y Y \underline{\text { Term }}>S_{2}$, indicating that the term is referenced from all past and future editions of that standard.

Table 2

Examples of normative dependencies from published standards

\begin{tabular}{|c|c|}
\hline Normative dependency & Reference \\
\hline $\begin{array}{l}\text { ISO/TS 19139:2007 Scope> ISO } 19115 \text { [This Technical Specification defines } \\
\text { Geographic MetaData XML (gmd) encoding, an XML Schema implementation } \\
\text { derived from ISO 19115, Geographic information - Metadata.] }\end{array}$ & [11], clause 1 \\
\hline ISO $19112: 2003$ Rref> ISO $19105: 2000$ & {$[4]$, clause 3} \\
\hline ISO 19128:2005 $\stackrel{\mathrm{NRef}>}{\longrightarrow}$ ISO 19111 & {$[5]$, clause 3} \\
\hline ISO 19118:2005 Term > ISO 19101 [feature] & [12], subclause 4.1 \\
\hline ISO 19128:2005 Term> ISO 19111[coordinate system] & [5], subclause 4.3 \\
\hline $\begin{array}{l}\text { ISO 19118:2005 Requirement> ISO/TS 19103:2005 [The application schema used for } \\
\text { encoding in compliance with this International Standard shall be written in the } \\
\text { UML conceptual schema language, in accordance with ISO/TS } 19103 \text { and ISO } \\
\text { 19109.] }\end{array}$ & {$[12]$, subclause 6.3} \\
\hline $\begin{array}{l}\text { ISO 19119:2005 Recommendation> ISO 19118:2005 [As relevant, a platform-specific } \\
\text { specification should include the encoding of information according to ISO 19118.] }\end{array}$ & [13], subclause 10.3 \\
\hline $\begin{array}{l}\text { ISO 19112:2005 RequirementUML> ISO 19111:2003 } \\
\text { [SI_SpatialReferenceSystemUsingGeographicIdentifiers is derived from } \\
\text { RS_ReferenceSystem] }\end{array}$ & $\begin{array}{l}{[4], \text { Figure } 5 \text { in }} \\
\text { subclause } 7.1\end{array}$ \\
\hline ISO 19128:2005 RecommendationUML> ISO 19115:2003 [CI_ResponsibleParty] & {$[5]$, Table 5} \\
\hline
\end{tabular}

Provisions stipulate requirements and recommendations that an implementation of the standard has to follow in order to claim compliance. A requirement is an 'expression in the content of a document conveying criteria to be fulfilled if compliance with the document is to be claimed and from which no deviation is permitted'. A recommendation is an 'expression in the content of a document conveying that among several possibilities one is recommended as 
particularly suitable, without mentioning or excluding others, or that a certain course of action is preferred but not necessarily required, or that (in the negative form) a certain possibility or course of action is deprecated but not prohibited' [10]. A separate operator is used to distinguish normative dependencies involving Unified Modelling language (UML) elements, e.g. $S_{1}: Y Y Y Y$ RequirementUML $>S_{2}$. The object-oriented nature of UML allows the use of traditional objectoriented dependency analysis techniques and therefore these provisions are distinguished from other free text provisions.

Now that the normative dependencies have been defined and explained, the next step is to understand the implications of changes to the normative content on normative dependencies. Continuing with the normative dependency notation introduced above, $S_{1}: Y Y Y Y^{\prime}$ is now the revision of $S_{1}: Y Y Y Y$. If $S_{1}: Y Y Y Y$ is revised, the normative content in $S_{1}: Y Y Y Y^{\prime}$ can be modified without any impact on existing normative dependencies in which $S_{1}: Y Y Y Y$ is the left operand. If $S_{1}: Y Y Y Y$ appears as the right operand in any normative dependencies (i.e. dated dependencies), modifications in the normative content of $S_{1}: Y Y Y Y^{\prime}$ will not violate these dependencies (there are other considerations, such as backward compatibility though). However, if $S_{1}$ appears as the right operand in any normative dependencies (i.e. undated dependencies), there are restrictions on the modifications that can be introduced in the normative content of $S_{1}: Y Y Y Y^{\prime}$. Table 3 explains these restrictions on $S_{1}: Y Y Y Y^{\prime}$.

Table 3

Restrictions on the normative content of $S_{1}$ :YYYY', the revision of $S_{1}: Y Y Y Y$

\begin{tabular}{|c|c|}
\hline Existing normative dependency & Restrictions on $\mathrm{S}_{1}: \mathrm{YYYY}^{\prime}$ \\
\hline $\mathrm{S}_{2}: \mathrm{YYYY} \underline{\text { Scope }}>\mathrm{S}_{1}[$ dependency] & $\begin{array}{l}\text { Existing implementations of } \mathrm{S}_{2} \text { :YYYY shall comply with } \\
\mathrm{S}_{1}: \mathrm{YYYY}^{\prime} \text {. }\end{array}$ \\
\hline $\mathrm{S}_{2}:$ YYYY $\underline{\mathrm{NRef}}>\mathrm{S}_{1}$ & $\begin{array}{l}\mathrm{S}_{1}: Y_{Y Y Y^{\prime}} \text { shall include the normative content that makes it } \\
\text { indispensable to the implementation of } S_{2}: Y Y Y Y \text {. }\end{array}$ \\
\hline $\mathrm{S}_{2}: \mathrm{YYYY} \underline{\text { Term }}>\mathrm{S}_{1}[$ term $]$ & $\begin{array}{l}\text { The term shall be included in } \mathrm{S}_{1} \text { :YYYY' with the same } \\
\text { meaning. }\end{array}$ \\
\hline $\mathrm{S}_{2}: Y Y Y Y$ Requirement $>S_{1}$ [requirement] & $\begin{array}{l}\text { The requirement as implemented in existing } \\
\text { implementations of } S_{2} \text { :YYYY shall comply with } S_{1}: Y Y Y Y\end{array}$ \\
\hline $\mathrm{S}_{2}: \mathrm{YYYY}$ Recommendation $>\mathrm{S}_{1}$ [recommendation] & $\begin{array}{l}\text { The recommendation as implemented in existing } \\
\text { implementations of } S_{2} \text { :YYYY shall comply with } S_{1}: Y Y Y Y^{\prime}\end{array}$ \\
\hline $\mathrm{S}_{2}: \mathrm{YYYY} \stackrel{\text { RequirementUML }>}{ } \mathrm{S}_{1}[$ UML element $]$ & $\begin{array}{l}\text { The UML element is included in } \mathrm{S}_{1} \text { :YYYY' so that existing } \\
\text { implementations of } \mathrm{S}_{2} \text { :YYYY comply with } \mathrm{S}_{1}: Y_{Y Y Y} \text {. }\end{array}$ \\
\hline $\mathrm{S}_{2}: \mathrm{YYYY}$ RecommendationUML $>\mathrm{S}_{1}$ [UML element $]$ & $\begin{array}{l}\text { The UML element is included in } \mathrm{S}_{1} \text { :YYYY' so that existing } \\
\text { implementations of } \mathrm{S}_{2} \text { :YYYY comply with } \mathrm{S}_{1}: Y_{Y Y Y} \text {. }\end{array}$ \\
\hline
\end{tabular}

\section{Normative dependency analysis of geographic information standards}

One of the challenges of standard harmonization is the maintenance of standards when revisions are required. It is a challenge to determine whether a change in a revised standard affects other standards, and how. Normative dependencies are established after the standard on the left of a normative dependency relation is published. For this reason, the normative dependencies cannot be published in the left hand standard itself; instead, they are published in the individual dependent standards. In this section the data model that was used in the normative dependency analysis of ISO 19100 standards is presented and a description is provided of how the analysis was done. 


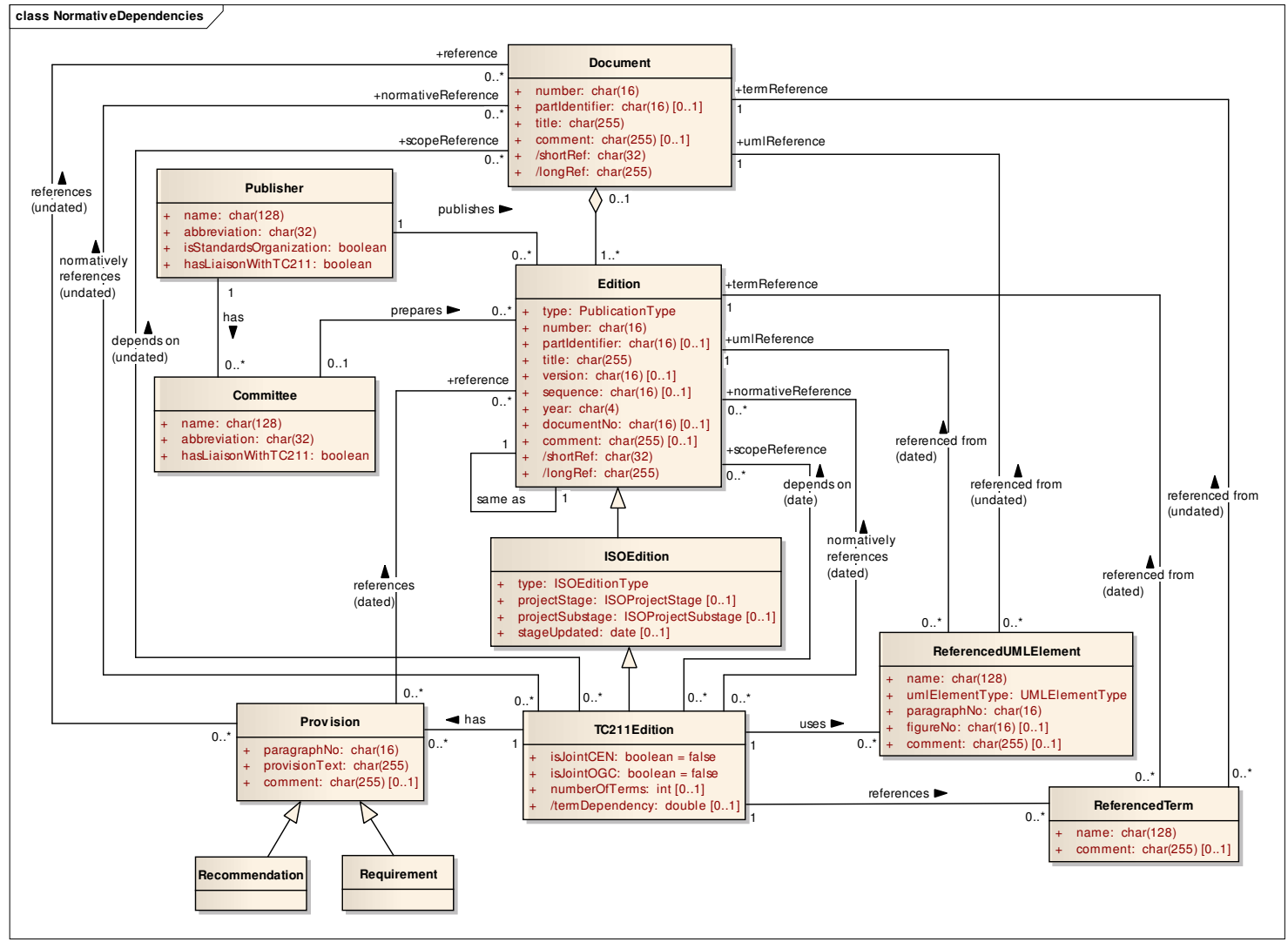

Fig. 1. Normative dependency data model

Fig.1 shows a data model in UML that was developed as part of this research for the representation of normative dependencies. This data model was used as the blueprint for the database in which the normative dependencies between ISO 19100 standards were recorded and subsequently analyzed. More information about the database is available in [13].

In the model the Edition class represents a specific edition (publication) of a document and thus always has a year of publication associated with it. If there is more than one edition of the same document, the editions are associated with a single document. For example, ISO 19111 is an instance of the Document class and ISO 19111:2003 [15] and ISO 19111:2007 [16] are two instances of the Edition class, associated with the ISO 19111 document.

The reflexive 'same as'-association of the Edition class represents standards that are developed and published jointly with other organizations. ISOEdition and TC211Edition are derived from the Edition and ISOEdition classes respectively, each defining additional ISO- and ISO/TC 211specific attributes. A modification of an edition, such as a supplement, corrigendum or amendment, has the same associations as the TC211Edition and Edition classes, but these are not included in the figure to keep the diagram simple.

Normative dependencies are represented by associations between classes. For example, the $S_{1}: Y Y Y Y$ NRef> $S_{2}: Y Y Y Y$ normative dependency relation is represented by the association labelled 'normatively references (dated)' between Edition and TC211Edition: an instance of the TC211Edition class normatively references zero or more instances of the Edition class; and an instance of the Edition class is normatively referenced in zero or more instances of the TC211Edition class. As another example, the $S_{1}: Y Y Y Y$ Requirement $>S_{2}$ and $S_{1}: Y Y Y Y$ Recommendation $>S_{2}$ normative dependency relations are represented by the association labelled 'references (undated)' between the Provision and Document class. 
The following normative dependencies between ISO 19100 standards were recorded for the analysis:

- Scope dependencies in all published ISO 19100 standards

- Normative reference dependencies in all published ISO 19100 standards

- Term dependencies in all published ISO 19100 standards

- A selected number of provision dependencies from a subset of ISO 19100 standards

The Harmonized Model Maintenance Group (HMMG) of ISO/TC 211 maintains a harmonized model of all UML elements defined in the ISO 19100 series of standards. This model ensures that UML elements in the ISO 19100 series of standards are harmonized. Dependencies between the UML elements of various standards are implicitly included in the model. For example, the ISO 19112:2005 RequirementUML > ISO 19111:2003 [RS_ReferenceSystem] dependency (SI_SpatialReferenceSystemUsingGeographicIdentifiers in ISO 19112:2005 is derived from RS_ReferenceSystem in ISO 19111) [4] is included in the harmonized data model. Dependency analysis is done on the UML directly and the UML dependencies were therefore not recorded again.

Once all the dependencies were recorded, an overview of the type of dependencies was obtained. Selected dependencies were analyzed individually in an attempt to better understand the impact of these dependencies on standard maintenance.

\section{Results and discussion of the normative dependency analysis}

In this section the results of the normative dependency analysis are presented. The discussion is presented in the subsequent sub-sections in the order of scope, normative reference, term and provision dependencies.

\subsection{Scope dependencies}

The number of scope dependencies in the ISO 19100 standards is limited to twenty. In comparison, there are 299 normative reference dependencies and 571 term dependencies. Most of the scope dependencies are undated, implying that a revision to the 'other' standard (on which the scope statement depends) has to ensure backward compatibility. A single ISO 19100 scope statement references the other standard explicitly with a date. Most scope dependencies are ambiguously referenced: the other standard is referenced without a date in the scope statement, but listed as a normative reference with a date. One can probably assume that these references are dated references by implication of the dated normative reference. However, including the date in the scope statement itself, removes all potential ambiguity.

Table 4 shows four scope dependencies from the ISO 19100 suite of standards. The first scope dependency is a trivial example of a second part of a standard that depends on the first or main part of the standard. In this case ISO 19111-2:2009, Geographic information - Spatial referencing by geographic coordinates - Part 2: Extension for parametric value [17], depends on ISO 19111, Geographic information - Spatial referencing by geographic coordinates. The second scope dependency in Table 4 is an example of one standard relying quite heavily on another standard. In both examples, the reference in the scope statement is undated, but the other standard is included in the list of normative references with a date.

Two ISO 19100 scope statements depend on another standard that is not included in the list of normative references, but in the bibliography. The third and fourth scope dependencies in Table 4 refer. Such a normative dependency is questionable: if the dependency is described in the scope statement, it is highly likely that the other standard is indispensable for the application of 
the document'. On the other hand, if the other standard is not 'indispensable for the application of the document', should the dependency be described in the scope statement?

Table 4

Four scope dependencies in the ISO 19100 series of standards

\begin{tabular}{ccl}
\hline No & $\begin{array}{c}\text { Dependent } \\
\text { standard }\end{array}$ & \multicolumn{1}{c}{ Dependency statement } \\
\hline 1 & ISO 19111-2:2009 & $\begin{array}{l}\text { It applies the schema of ISO 19111 to combine a position referenced by } \\
\text { coordinates with a parametric value to form a spatio-parametric coordinate } \\
\text { reference system. [17] } \\
\text { This International Standard specifies a schema for feature concept } \\
\text { dictionaries to be established and managed as registers. ... These registers are } \\
\text { in accordance with ISO 19135. [18] }\end{array}$ \\
& ISO 19126:2009 & $\begin{array}{l}\text { This International Standard addresses for an LBS system the first three basic } \\
\text { viewpoints as defined in the Reference Model for Open Distributed } \\
\text { Processing (RM-ODP; see ISO/IEC 10746-1). [19] }\end{array}$ \\
3 & ISO 19132:2007 & $\begin{array}{l}\text { This International Standard defines a core profile of ISO 19107 that specifies, } \\
\text { in accordance with ISO 19106, a minimal set of geometric elements necessary } \\
\text { for efficient creation of application schemata. [20] }\end{array}$ \\
\hline 4 & ISO 19137:2007 &
\end{tabular}

\subsection{Normative reference dependencies}

The normative reference dependency analysis provides an overview of normative reference information, which is especially useful when revising right operands of a normative dependency relation. At a single glance one can see the list of editions that normatively reference the standard to be revised. For example, ISO 19101:2002, Geographic information - Reference model [21] is currently being revised. ISO 19117:2005 and ISO 19134:2007 are the only standards that normatively references ISO 19101 without a date [22][23], thus the revision of ISO 19101:2002 has to include the normative content that is required to understand ISO 19117:2005 and ISO 19134:2007.

The analysis of normative reference dependencies further identifies standards that are potentially heavily depended upon. For example, ISO 19115:2003, Geographic information Metadata [24] is normatively referenced in twenty one ISO 19100 standards and ISO 19115 (without date) is normatively referenced in another five standards. Among the documents that are normatively referenced without a date, ISO 19108 and ISO 19107 are top. Table 5 shows the top most normatively referenced ISO 19100 standards.

Table 5

Top most normatively referenced ISO 19100 standards

\begin{tabular}{cc|cc}
\hline Edition & $\begin{array}{c}\text { Number of times } \\
\text { normatively referenced }\end{array}$ & Document & $\begin{array}{c}\text { Number of times } \\
\text { normatively referenced }\end{array}$ \\
\hline ISO 19115:2003 & 21 & ISO 19107 & 9 \\
ISO/TS 19103:2005 & 17 & ISO 19108 & 7 \\
ISO 19109:2005 & 13 & ISO 19123 & 5 \\
ISO 19107:2003 & 12 & ISO 19112 & 5 \\
ISO 19108:2002 & 9 & ISO 19109 & 5 \\
ISO 19111:2003 & 8 & ISO 19115 & \\
\hline
\end{tabular}

A number of circular normative references are revealed by the analysis, shown in Table 6. All of these involve specific editions of a standard (as opposed to undated normative references). Ideally, standards involved in a circular normative reference should be revised simultaneously, so that the revised editions can normatively reference each other again. In practice, resources 
are seldom available to do that. Because the list of normative references in an ISO standard lists documents that are indispensable to the application of the document, i.e. not necessarily depended upon, the normative reference dependency is an indicator but does not provide sufficient details about the actual dependency. It is necessary to understand the details of the normative dependencies involved in order to understand which one of the standards should be revised first and how normative content of a standard that is involved in a normative reference dependency may be modified. In the subsequent section 4.4, some provisions of standards involved in circular normative references dependencies are discussed to illustrate this further.

Table 6

Circular normative reference dependencies between ISO 19100 standards

\begin{tabular}{|c|}
\hline Circular normative references \\
\hline ISO 19107:2003 Nef> ISO 19109:2005 ㅅef> ISO 19107:2003 \\
\hline ISO 19108:2002 Nef> ISO 19109:2005 $\underline{\mathrm{NRef}>}$ ISO 19108:2002 \\
\hline 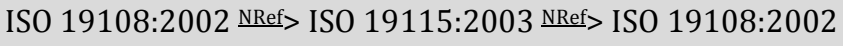 \\
\hline 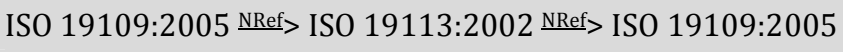 \\
\hline 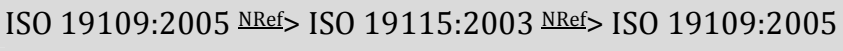 \\
\hline ISO 19110:2005 NRef> ISO 19115:2003 ㅅef> ISO 19110:2005 \\
\hline ISO $19112: 2003 \stackrel{\mathrm{NRef}>}{\longrightarrow}$ ISO $19115: 2003 \stackrel{\mathrm{NRef}>}{\mathrm{ISO}} 19112: 2003$ \\
\hline 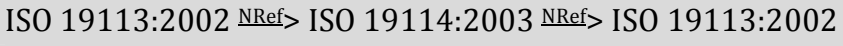 \\
\hline 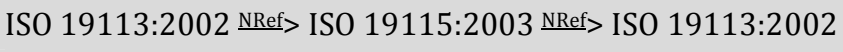 \\
\hline 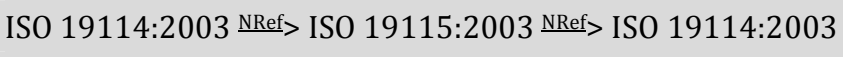 \\
\hline ISO 19115:2003 Nef> ISO 19117:2005 ㅅef> ISO 19115:2003 \\
\hline
\end{tabular}

\subsection{Term dependencies}

Similar to the normative reference dependency analysis, the term dependency analysis reveals which standards are heavily relied upon for terminology. There are some obvious overlaps between Table 7, which lists standards from where terms are most often repeated, and Table 5, which lists the standards most normatively referenced ISO 19100 standards. Among, the standards that appear in both tables are those that standardize the very basics of geographic information, as well as the way in which other standards should be written. Examples are ISO 19101, Geographic information - Reference model [21], ISO/TS 19103, Geographic information Conceptual schema language [25], ISO 19111, Geographic information - Spatial referencing by geographic coordinates [15] and ISO 19115, Geographic information - Metadata [24][23].

Table 7

Top ISO 19100 standards from which terms are repeated in other ISO 19100 standards

\begin{tabular}{cc|cc}
\hline $\begin{array}{c}\text { Edition where term is } \\
\text { defined }\end{array}$ & $\begin{array}{c}\text { Number of times a } \\
\text { term is repeated }\end{array}$ & $\begin{array}{c}\text { Document where } \\
\text { term is defined }\end{array}$ & $\begin{array}{c}\text { Number of times a } \\
\text { term is repeated }\end{array}$ \\
\hline ISO 19107:2003 & 45 & ISO 19101 & 58 \\
ISO 19111:2007 & 32 & ISO 19107 & 28 \\
ISO 19123:2005 & 22 & ISO 19133 & 27 \\
ISO 19101:2002 & 21 & ISO 19111 & 19 \\
ISO 19133:2005 & 15 & ISO 19115 & 19 \\
ISO 19135:2005 & 12 & ISO 19103 & 10 \\
\hline
\end{tabular}

Table 8 shows a list of terms from ISO 19101 that are repeated in other standards. In some cases the term is referenced from ISO 19101:2001, in others the term is referenced without a date. As long as the semantics of a term's definition remain the same, the actual wording of the 
definition may be modified in a revision of ISO 19101:2002. If however, the semantics of the definition change, a new term for the new definition has to be introduced. Strictly speaking, if a term is referenced without a date, it can never be removed from any future revision of that standard. Thus, dated term references make it easier to maintain terms in revisions. The large number of undated term references in ISO 19100 standards is a concern from a term maintenance point of view.

Table 8

Term dependencies on ISO 19101:2002 and ISO 19101

\begin{tabular}{lcc}
\hline \multicolumn{1}{c}{ Term } & $\begin{array}{c}\text { Number of times referenced } \\
\text { from ISO 19101:2002 }\end{array}$ & $\begin{array}{c}\text { Number of times referenced } \\
\text { from ISO 19101 }\end{array}$ \\
\hline application & 0 & 5 \\
application schema & 2 & 6 \\
conceptual model & 0 & 4 \\
conceptual schema & 0 & 4 \\
feature & 8 & 12 \\
feature association & 3 & 4 \\
feature attribute & 3 & 10 \\
geographic information & 3 & 4 \\
quality & 1 & 3 \\
schema & 2 & 2 \\
universe of discourse & 0 & 5 \\
\hline
\end{tabular}

Table 9 shows the term dependencies for the 'coordinate reference system' term, which is defined in ISO 19111. This term is an interesting example of a change of definition introduced in a revision. ISO 19111:2003 defines a 'coordinate reference system' as a 'coordinate system that is related to the real world by a datum' [15]. In ISO 19111:2007, the definition is changed to 'coordinate system that is related to an object by a datum' [16]. The 2003 definition was too restrictive and the change in definition recognises the fact that a coordinate reference system could be related to any object, including for example a remote sensing satellite, rather than just the Earth. Because the 'real world' is an 'object', previous use of the definition is not rendered incompatible by the new definition (Andrew Jones, 9 August 2009, Personal communication).

Table 9

Term dependencies on 'coordinate reference system'

\section{Term dependency}

ISO 19107:2003 Term> ISO 19111 [coordinate reference system]

ISO 19116:2004 Term> ISO 19111 [coordinate reference system]

ISO 19123:2005 Term > ISO 19111:2003 [coordinate reference system]

ISO 19125-1:2004 Term> ISO 19111 [coordinate reference system]

ISO 19128:2005 Term> ISO 19111 [coordinate reference system]

ISO/TS 19130:2010 Term> ISO 19111:2007 [coordinate reference system]

ISO 19136:2006 Term> ISO 19111:2007 [coordinate reference system]

ISO/TS 19129:2009 Term> ISO 19111:2007 [coordinate reference system]

ISO 19142:2010 Term> ISO 19111:2007 [coordinate reference system]

ISO 19143:2010 Term > ISO 19111:2007 [coordinate reference system] 
The normative dependency analysis reveals not only which technical committees and organizations are involved in normative dependency relationships with ISO 19100 standards, but also what the nature of these relationships is. For example, Table 10 shows the committees from whose standards the ISO 19100 series of standards repeat one or more terms. The 'foreign' standards are always right operands in the normative dependency relations of the analysis. To include the inverse as well, all standards with a normative dependency on an ISO 19100 standard have to be included in the analysis. While it is impractical to search all documents 'out there', it would be beneficial to understand at least the normative dependency relationships among publications of different ISO technical committees.

Table 10

Committees with which ISO 19100 standards have a term dependency relationships

\begin{tabular}{|c|c|}
\hline Committee Abbreviation & Committee Name \\
\hline CEOS WGCV & Working Group on Calibration and Validation \\
\hline IETF Networking WG & Networking Working Group \\
\hline ISO TMB & Technical Management Board \\
\hline ISO/IEC JTC 1 & Information technology \\
\hline ISO/IEC JTC 1/SC 22 & $\begin{array}{l}\text { Programming languages, their environments and system software } \\
\text { interfaces }\end{array}$ \\
\hline ISO/IEC JTC 1/SC 29 & Coding of audio, picture, multimedia and hypermedia information \\
\hline ISO/IEC JTC $1 /$ SC 32 & Data management and interchange \\
\hline ISO/IEC JTC $1 /$ SC 7 & Software and systems engineering \\
\hline ISO/TC 12 & Quantities and units \\
\hline ISO/TC 154 & $\begin{array}{l}\text { Processes, data elements and documents in commerce, industry and } \\
\text { administration }\end{array}$ \\
\hline ISO/TC 211 & Geographic information/Geomatics \\
\hline ISO/TC $37 / \mathrm{SC} 1$ & Principles and methods \\
\hline ISO/TC 37/SC3 & Systems to manage terminology, knowledge and content \\
\hline ISO/TC 42 & Photography \\
\hline ISO/TC 46 & Information and documentation \\
\hline ISO/TC 69/SC 1 & Terminology and symbols \\
\hline ISO/TC 69/SC 5 & Acceptance sampling \\
\hline ITU-R SG07 & Radio communication, Study group on science services \\
\hline ITU-T SG 13 & Telecommunication standardization, Study group on future networks \\
\hline OMG/UML & Unified Modeling Language \\
\hline UN FAO & UNFAO \\
\hline W3C & World Wide Web Consortium \\
\hline
\end{tabular}

\subsection{Provision dependencies}

The types of dependencies analyzed until now, are quite easily located: the scope, normative references, and terms and definitions sections appear at the beginning of an ISO document. The scope statement is usually reasonably short so that one can read through it to determine any dependencies; the normative references section comprises a list of references; and each term is defined in it its own subclause. Provisions, however, are embedded in the text of the remainder of the document and are identified through the verbal forms that are used to express each kind of provision, i.e. shall and shall not for requirements; and should and should not for recommendations. For each of these verbal forms, there are equivalent expressions, for 
example, 'has to', 'is required to' and 'it is necessary' for shall, and 'ought to' and 'it is recommended that' for should [10].

The following algorithm for the identification of requirement dependencies was followed during the normative dependency analysis that is described in this paper:

1. Search for the first 'shall' in the document's text, subsequent to the terms and definitions section.

2. Identify the text around the 'shall' that constitutes the provision (could be more than one sentence).

3. Identify any references to other documents in the provision text and determine whether the reference is a normative dependency, i.e. a change to the normative content of the referenced document affects this provision.

4. Search for the next 'shall' in the text and repeat steps 2 to 4 until the end of the document.

The process for the identification of recommendations is identical, except that one searches for 'should' instead of 'shall'. Theoretically, this process should find all requirements and recommendations. Unfortunately, some provisions are 'hidden' in the text. Consider, for example, the following paragraph from subclause 6.1 in ISO 19107:2003 [26]. For easier reference the sentences in the paragraph are numbered.

1. The geometry packages (Figure 4) contain the various classes for coordinate geometry.

2. All of these classes through the root class GM_Object inherit an optional association to a coordinate reference system.

3. All direct positions exposed through the interfaces defined in this International Standard shall be in the coordinate reference system of the geometric object accessed.

4. All elements of a geometric complex, composite, or aggregate shall be associated to the same coordinate reference system.

5. When instances of GM_Object are aggregated in another GM_Object (such as a GM_Aggregate, or GM_Complex) which already has a coordinate reference system specified, then these elements are assumed to be in that same coordinate reference system unless otherwise specified.

The 'shall' in the third and fourth sentence clearly identify them as requirements. Even though there is no 'shall' in the fifth sentence, the 'are assumed' suggests that it is a requirement equivalent to '...then it shall be assumed that these elements are in that same coordinate reference system unless otherwise specified'. One could also ask the question whether these three sentences represent three individual requirements, or whether they can be grouped into a single requirement. None of these provisions contain a dependency on another standard though, i.e. only some provisions rely on another standard. As an example of a provision dependency, the text below represents, ISO 19109:2005 Requirement> ISO 19108:2002[TM_Object]:

'GF_TemporalAttributeType represents a temporal attribute, which shall be used as the time reference characteristic of a feature. A temporal attribute type shall have a TM_Object as value type. The structure of TM_Object is defined in the Temporal Schema described in ISO 19108.' [27]

As described in the Introduction, the ISO/TC 211 committee collaborates with other standards organizations on geographic information standards. Some of these organizations have adopted formatting rules for easier identification of provisions. In order to achieve the INSPIRE goals of data sharing, a number of data specifications are published as guidelines for the spatial data themes referred to in Annex I of the INSPIRE Directive [28]. In these data specifications, requirements and recommendations are numbered and formatted into a box. Fig. 2 shows an 
example. In the original 'Requirement 2' and 'Requirement 3' are red and 'Recommendation 1' is blue (the provision text is in normal black font).

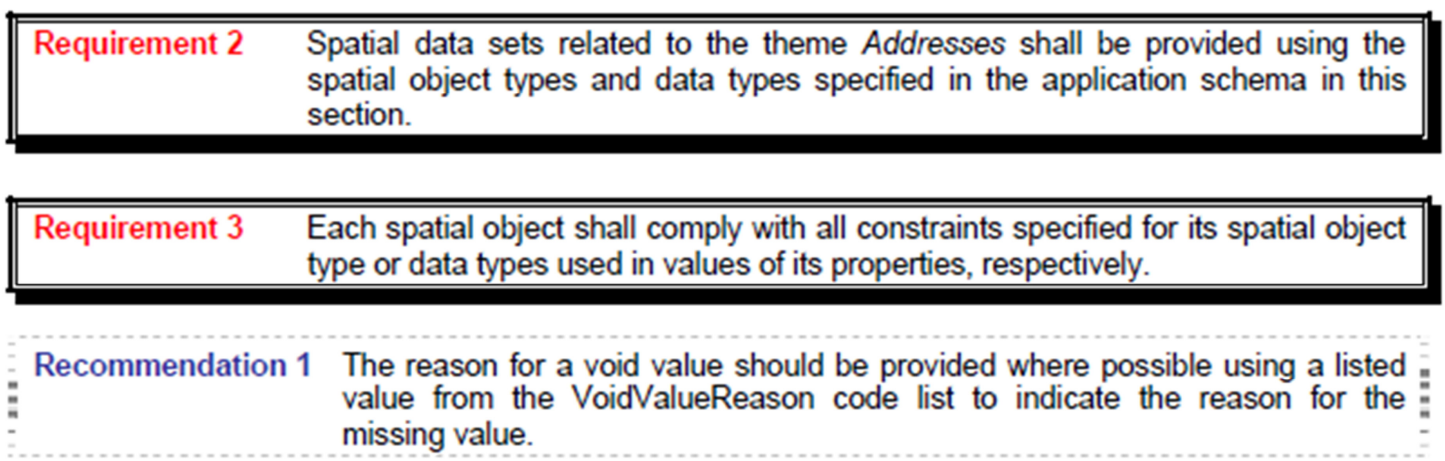

Fig. 2. An example of provision formatting from the INSPRE data specification on addresses [7]

Another example is the OGC's specification model for the writing of OGC specifications [29]. In contrast to the ISO/TC211 committee, the OGC spends large amounts of resources on conformance testing and this document specifies how requirements should be written to facilitate implementation and conformance testing. While the formatting used in this OGC document does not seem to be part of its specifications, it is very useful for the identification of requirements. Each requirement in the specification has a unique number; a 'Table of Requirements' with page numbers at the beginning of the document provides quick access to individual requirements in the specification; and the requirements are highlighted in the text by formatting them in a different bold font in red.

Table 6 in section 4.2 shows that there is a circular normative reference dependency between ISO 19108:2002 [30], Geographic information - Temporal schema and ISO 19109:2005, Geographic information - Rules for application schema. Closer inspection of the provisions in these two standards shows that the TM_Object class is defined in ISO 19108:2002 and ISO 19109:2005 specifies where and how this class is used in an application schema, thus ISO 19109:2005 Requirement> ISO 19108:2002. This dependency is at a class level representing a low coupling between the two standards: a change to the structure of TM_Object does not affect ISO 19109:2005. For the inverse dependency relation ISO 19108:2002 extends the rules for instantiating metaclasses in an application schema, i.e. ISO 19108:2002 Requirement> ISO 19109:2005 [Rules for application schema]. This coupling is tighter: a change to the relevant rule in ISO 19109:2005, might affect how the rule can be extended in ISO 19108:2002. Based on these interdependencies, the revision of ISO 19108:2002 should follow the revision of ISO 19109:2005.

Apart from circular normative dependencies, a chain of normative dependencies also dictates the order in which revisions should be done. For example, based on the chain of provision dependencies below, the standards should be revised in the order of first ISO 19107:2003, then ISO 19109:2005 and finally ISO 19108:2002.

\section{ISO 19108:2002 Requirement> ISO 19109:2005 [Rules for application schema] ISO 19109:2005 Requirement> ISO 19107:2003 [GM_Object]}

The provision dependencies discussed in this section illustrate the difficulties of identifying provisions and dependencies in a textual standard. Provisions have to be fulfilled in order to implement a standard. Thus, making it easier for standard implementers to identify the requirements and recommendations specified in a standard facilitates implementations of those 
standards. It further facilitates maintenance of the standards because the dependencies can be identified in the identified provisions.

In another example where a table of provisions at the beginning of a standard would have been useful, Walker [31],[32] analyzed and compared the provisions of a number of quality and process-related standards, including ISO 9001:2008 [33], in order to identify process activities and informational items that are included in one standard but not the other. The results of the analysis are used to improve the standards but also to assist implementers of more than one of these standards in understanding how the standards are related to each other. Provisions had to be identified manually and the analysis would have been a lot easier with a table of provisions.

An additional benefit of having access to provision dependency information for a standard is that this information can be used to verify the list of normative dependencies in a standard: if a standard depends on another standard, it is highly likely that the 'other' standard should be included in the list of normative references. In this way the normative dependency analysis contributes to the quality of a standard.

\section{Conclusion}

In this paper a normative dependency between two standards was defined, a notation for these introduced, a normative dependency data model presented, a normative dependency analysis of geographic information standards was described and results from the analysis discussed. For the analysis, normative dependencies between published ISO 19100 standards and other standards were analyzed.

Results from the normative dependency analysis show that:

- A normative dependency analysis provides an in-depth understanding of the interdependencies among standards.

- A normative reference dependency between two standards does not provide enough detail about the actual dependency between the two standards.

- Normative dependencies on specific editions (dated references) result in less restrictions when revisions have to be undertaken during standard maintenance.

- The formatting of ISO standards makes it difficult to identify the requirements of a standard, as well as the normative dependencies between standards.

- Low coupling between standards improves maintainability of the standards.

- There is potential for ambiguity if a standard is referenced differently in the text (without a date) than in the list of normative references (with a date).

Based on these results, the following recommendations are made:

- Normative dependencies between standards should be loosely coupled.

- Unless there is good justification, normative references should be dated.

- Explicitly identify requirements and recommendations in a standard, for example, by providing a table of requirements or by unique formatting of the provisions.

- Identify the normative dependencies of a standard, for example, by providing a table of normative dependencies at the beginning of the document.

- Verify the list of normative references against the list of normative dependencies.

- Use normative dependency relations to determine the order of revisions.

- Cite normatively referenced standards consistently in a standard, either with or without a date.

Following these recommendations, improves maintainability of standards. As an additional benefit, the standards are easier to implement and test, and the quality of the standards is 
improved. The recommendations do not apply to geographic information standards only, but are applicable to any standard.

While it is impractical to search all documents 'out there' for normative dependencies on the ISO 19100 series of standards, it would be interesting to see which normative dependency relationships exist between publications of different ISO technical committees. It would be easy to adapt the normative dependency data model for such an exercise.

For this normative dependency analysis, a selected number of provision dependencies were identified and analyzed. In order to obtain an overview of interdependencies among all ISO 19100 standards, all provision dependencies have to be analyzed. On a slightly larger scale one could include standards from collaborating organizations, such as the OGC. Students at the University of Pretoria are currently investigating automating the process of identifying provisions in a standard. While it is quite easy to identify sentences that contain the word 'shall' as a starting point for a list of provisions, manual intervention is required to group these sentences into individual logical requirements. Identifying requirements that do not contain a 'shall' in the normative text is an even bigger challenge.

While the normative dependency analysis considers relationships between standards, existing implementations of standards are not within the scope of the analysis. However, since it is impossible to know where and how many times a standard is implemented, standard maintenance decisions should always consider backward compatibility. To illustrate the importance of backward compatibility for geographic information, consider a standard for land cover classification according to which satellite images are classified at high costs over a couple of years in order to monitor climate change. If a revision changes the standard in such a way that data classified according to the new standard cannot be compared with data classified according to the previous standard, the old data becomes useless (or more likely, the new standard will not be implemented).

Sometimes a revision of an informative reference could invalidate the text in a standard. A future study could include informative dependencies. This would also reveal, overall, the nature of informative references used in standards: for example, are other standards, books, academic journals or conference proceedings preferred as informative references? However, the valueadd from an informative dependency analysis would be significantly less than from a normative dependency analysis.

\section{Acknowledgements}

The author would like to thank the South African Bureau of Standards (SABS) for their continued support of the author as a member of the South African delegation to meetings of ISO/TC 211, Geographic information/Geomatics. The author acknowledges the contributions to the work on normative dependency analysis from various members of the ISO/TC 211 committee and the Programme Maintenance Group (PMG) specifically.

\section{References}

[1] Website of ISO/TC 211, Geographic Information/Geomatics, www.isotc211.org (accessed August 2010).

[2] Website of the Open Geospatial Consortium Inc, www.opengeospatial.org (accessed August 2010).

[3] Open Geospatial Consortium, Gazetteer Service -- Profile of the Web Feature Service Implementation Specification (2006).

[4] International Organization for Standardization, ISO 19112:2003, Geographic information -Spatial referencing by geographic identifiers (2003). 
[5] International Organization for Standardization, ISO 19128:2005, Geographic information -Web Map Service Interface (2005).

[6] Open Geospatial Consortium, OpenGIS® Web Map Server Implementation Specification 1.3.0 (2006).

[7] INSPIRE Thematic Working Group Addresses, D2.8.1.5 INSPIRE Data Specification on Addresses - Guidelines (2010), http://inspire.jrc.ec.europa.eu/index.cfm/pageid/2/list/3 (accessed August 2010)

[8] Dong X and Godfrey MW, System-level Usage Dependency Analysis of Object-Oriented Systems, International Conference on Software Maintenance ICSM 2007 (2007).

[9] Cyra L and Gorski J, SCF - A framework supporting achieving and assessing conformity with standards, Computer Standards and Interfaces, 33 (2011), pp80-95.

[10] International Organization for Standardization and International Electrotechnical Commission, ISO/IEC Directives, Part 2, Rules for the structure and drafting of International Standards, Fifth edition (2004).

[11] International Organization for Standardization, ISO/TS 19139:2007, Geographic information -- Metadata - XML schema implementation (2007).

[12] International Organization for Standardization, ISO 19118:2005, Geographic information -Encoding (2005).

[13]ISO/TC 211 PMG Chair, ISO/TC 211 dependency database, http://www.isotc211.org/pmg/dependencies.htm.

[14] International Organization for Standardization, ISO 19119:2005, Geographic information -Services (2005).

[15] International Organization for Standardization, ISO 19111:2003, Geographic information -Spatial referencing by coordinates (2003).

[16] International Organization for Standardization, ISO 19111:2007, Geographic information -Spatial referencing by coordinates (2007).

[17] International Organization for Standardization, ISO 19111-2:2009, Geographic information -Spatial referencing by coordinates -- Part 2: Extension for parametric values (2009).

[18] International Organization for Standardization, ISO 19126:2009, Geographic information -Feature concept dictionaries and registries (2009).

[19] International Organization for Standardization, ISO 19132:2007, Geographic information -Location-based services - Reference model (2007).

[20] International Organization for Standardization, ISO 19137:2007, Geographic information Core profile of the spatial schema (2007).

[21] International Organization for Standardization, ISO 19101:2002, Geographic information -Reference model (2002).

[22] International Organization for Standardization, ISO 19117:2005, Geographic information -Portrayal (2005).

[23] International Organization for standardization, ISO 19134:2007, Geographic information -Location based services -- Multimodal routing and navigation (2007).

[24] International Organization for Standardization, ISO 19115:2003, Geographic information -Metadata (2003).

[25] International Organization for Standardization, ISO/TS 19103:2005, Geographic information -- Conceptual schema language (2003).

[26] International Organization for Standardization, ISO 19107:2003, Geographic information -Spatial schema (2003).

[27] International Organization for Standardization, ISO 19109:2005, Geographic information -Rules for application schema (2005).

[28] Directive 2007/2 of the European Parliament and of the Council of 14 March 2007 establishing an Infrastructure for Spatial Information in the European Community (INSPIRE) (2007) http://inspire.jrc.ec.europa.eu/index.cfm/pageid/3 (accessed August 2010). 
[29] Open Geospatial Consortium, The Specification Model - A Standard for Modular specifications (2009) http://www.opengeospatial.org/ogc/policies/directives (accessed August 2010).

[30] International Organization for Standardization, ISO 19108:2001, Geographic information -Temporal schema (2008).

[31] Walker AJ, A conformant process reference model for ISO 9001, ISO/IEC 20000-1 and ISO/IEC 2700, Technical report produced for the SABS SC71E, Information Security and SABS SC71C, ICT Software and Systems Engineering committees (2010).

[32] Walker AJ, Evaluating the ISO TMB Management System Common Text proposal in terms of selection of candidate management system standards, SPI Laboratory (Pty) Ltd, Johannesburg, South Africa (2011).

[33] International Organization for Standardization, ISO 9001:2008, Quality management systems -- Requirements (2008). 